\title{
Embryonal Rhabdomyosarcoma in Mastoid and Middle Ear in a 3-Year-Old Girl: A Rare Case Report
}

\author{
Saman Vegari, ${ }^{1}$ Alireza Hemati, ${ }^{1}$ Hosein Baybordi, ${ }^{2}$ Leila Davarimajd, ${ }^{1}$ \\ and Ghasem Chatrbahr ${ }^{3}$ \\ ${ }^{1}$ Department of Otolaryngology Head and Neck Surgery, Tabriz Medical Sciences University, Tabriz 5174867773, Iran \\ ${ }^{2}$ Department of Pathology, Tabriz Medical Sciences University, Tabriz 5174867773, Iran \\ ${ }^{3}$ Department of Library, Tabriz Medical Sciences University, Tabriz 5174867773, Iran
}

Correspondence should be addressed to Saman Vegari, svegari@yahoo.com

Received 9 March 2012; Accepted 22 April 2012

Academic Editors: W. Issing, M. B. Naguib, and H. Sudhoff

Copyright (C 2012 Saman Vegari et al. This is an open access article distributed under the Creative Commons Attribution License, which permits unrestricted use, distribution, and reproduction in any medium, provided the original work is properly cited.

\begin{abstract}
Introduction. The most common sarcoma of childhood is rhabdomyosarcoma, approximately $35 \%$ of all paediatric rhabdomyosarcomas occur in the head and neck. Case Report. A 3-year-old girl referred to our clinic due to serosanguineous purulent discharge from her right ear. After paraclinical and pathologic evaluation it was diagnosed as embryonic rhabdomyosarcoma. Conclusions. In all children with mastoiditis, especially in young children, rhabdomyosarcoma should be considered as a differential diagnosis.
\end{abstract}

\section{Introduction}

The most common sarcoma of childhood is rhabdomyosarcoma $[1,2]$, this tumor is the third most common neoplasm in childhood after neuroblastoma and nephroblastoma [3, 4]. Approximately $35 \%$ of all paediatric rhabdomyosarcomas occur in the head and neck $[3,5]$. The most common site that involved by rhabdomyosarcoma is orbit (about one-third of cases). After that, in decreasing order, rhabdomyosarcoma affects oral cavity and pharynx (29\%), the face and neck region (24\%) [3], involvement of the ear and temporal bone with rhabdomyosarcoma is uncommon [6]. Pathologic subtypes of rhabdomyosarcoma include: embryonal, botryoid, alveolar, pleomorphic, spindle cell, and anaplastic variants [7]. The embryonal rhabdomyosarcoma includes about 60 $70 \%$ of rhabdomyosarcoma cases $[8,9]$.

\section{Case Presentation}

A 3-year-old girl referred to our clinic due to serosanguineous purulent discharge from her right ear. She was treated with antibiotics for a 3 -week period with attenuation in the amount of drainage. In physical examination, there was a polypoid, reddish and fragile mass that filled external ear canal in right side, facial nerve was intact, and there was fetor discharge from the ear canal. Biochemistry tests were normal. In computer tomography, soft tissue density was present in mastoid and middle ear. The mass involved external ear and projected from external auditory meatus. There was ragged erosion in mastoid air cells and external surface of mastoid bone (Figure 1). Therefore, first diagnosis was neoplastic change and rhabdomyosarcoma was most probably because of patient age, metastatic neuroblastoma, lymphoma and leukemia was in differential diagnosis. Patient admitted and biopsy were done from the mass, pathologist reported keratinizing squamous epithelium, granulation tissue and abscess formation. After 2-week radical mastoidectomy was done via postauricular. During surgery external auditory canal and mastoid was full of polypoid granulomatous tissue while tympanic membrane was intact without perforation. Two samples were prepared and sent to two different pathology laboratories, first pathologist reported granulation tissue and keratinizing squamous epithelium, while the second pathologist reported embryonal rhabdomyosarcoma (Figure 2). Then multiagent chemotherapy and radiotherapy were suggested to patient parents and they did not accept to keep on treatment. 


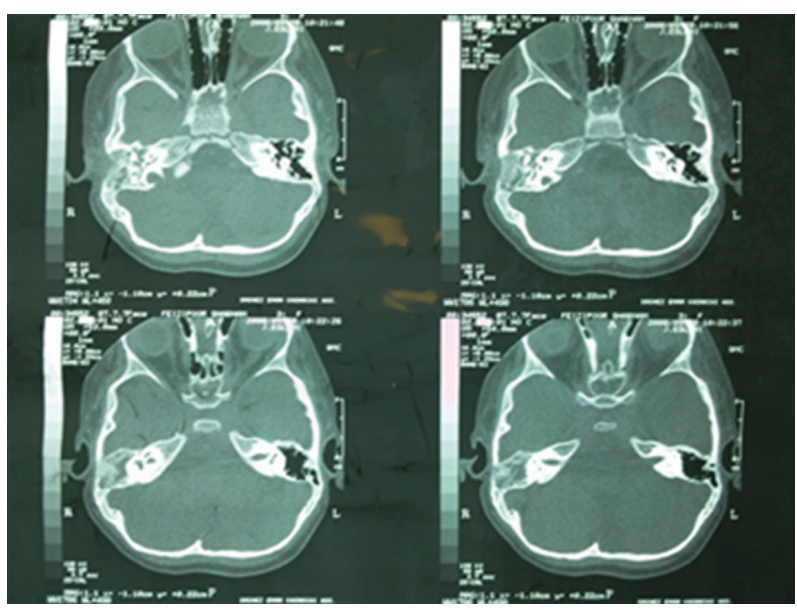

(a)

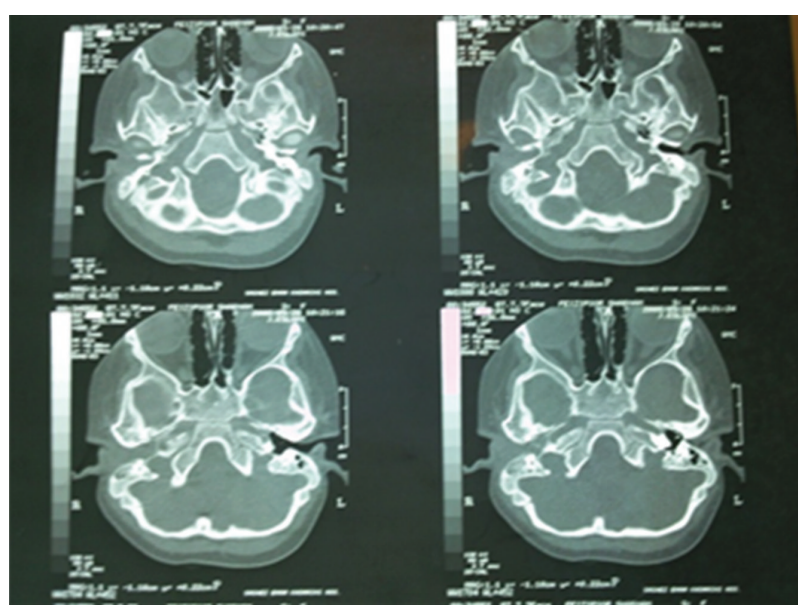

(b)

Figure 1: The mass involved external ear and projected from external auditory meatus. There was ragged erosion in mastoid air cells and external surface of mastoid bone.

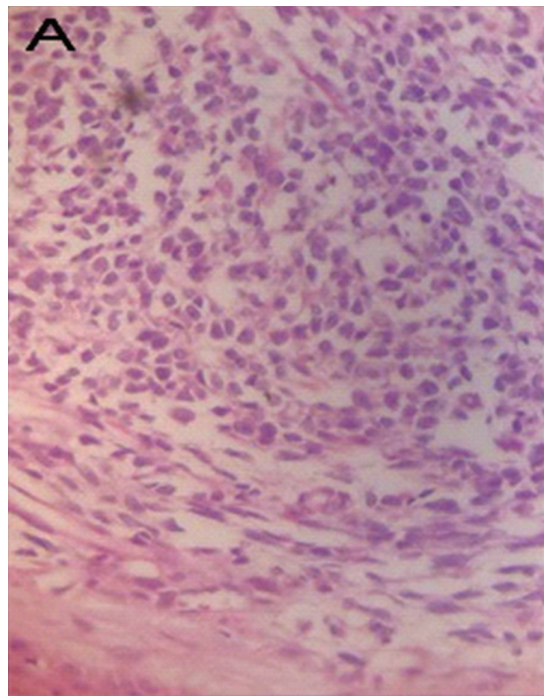

(a)

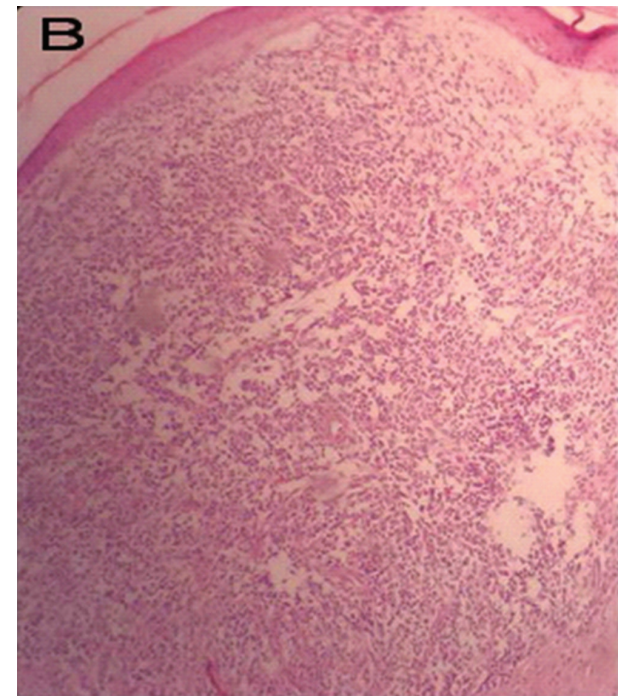

(b)

FIGURE 2: The cells show a combination of shapes but a spindle or elongated morphology is evident overall. Strap cells that look like primitive muscle cells that classically describe in rhabdomyosarcoma are seen in this pictures.

\section{Discussion}

Rhabdomyosarcomas may originate in any anatomical site, occurring predominantly in head and neck regions, orbits, skull base, nasal cavity, and nasopharynx, where there is little or no musculoskeletal tissue $[2,10]$. In pediatric cases, about 30 to $40 \%$ occur in the head and neck regions $[3,5,10]$; the ear and the temporal bone are uncommon sites of involvement. Chao et al. reported 3 patients with temporal bone involvement out of 102 cases [6].

In 1966 Potter reported a 3-year-old male with bilateral otitis media and polypoid mass in right external ear canal. The patient was diagnosed as having rhabdomyosarcoma [11].
Kukwa et al. in 2011 reported an embryonal rhabdomyosarcoma of the larynx in a 33-year-old man. After unsuccessful chemotherapy, hemilaryngectomy was performed. In follow-up CT no signs of recurrence were found. Recently patient was recurrence free for 62 months [12].

In 2008, Khatami et al. reported a case of congenital rhabdomyosarcoma in one-day-newborn, presented with huge mass in right hand and palpable lymph node in submaxillary [13].

In the 1960s, fewer than one-third of children with rhabdomyosarcoma survived, but cure rates are now approximatly $70 \%$, largely reflecting advances made by the Intergroup Rhabdomyosarcoma Study Committee (IRSC) [3]. 


\section{Conclusions}

In all children with mastoiditis, especially in young children, rhabdomyosarcoma should be considered as a differential diagnosis.

\section{References}

[1] M. Carli, M. Guglielmi, G. Sotti et al., "Soft-tissue sarcomas," in Paediatric Oncology, pp. 380-416, Chapman \& Hall, London, UK, 1997.

[2] K. Arita, K. Sugiyama, A. Tominaga, and F. Yamasaki, "Intrasellar rhabdomyosarcoma: case report," Neurosurgery, vol. 48, no. 3, pp. 677-680, 2001.

[3] J. M. Carol and J. H. Richard, "Pediatric head and neck malignancies," in Cummings Otolarymgology Head \& Neck Surgery, W. F. Paul, Ed., vol. 3, pp. 2835-2849, Mosby, Philadelphia, Pa, USA, 2010.

[4] C. A. Stiller and D. M. Parkin, "International variations in the incidence of childhood soft-tissue sarcomas," Paediatric and Perinatal Epidemiology, vol. 8, no. 1, pp. 107-119, 1994.

[5] T. K. Goto, K. Yoshiura, T. Tanaka et al., "A follow-up of rhabdomyosarcoma of the infratemporal fossa region in adults based on the magnetic resonance imaging findings: case reports," Oral Surgery, Oral Medicine, Oral Pathology, Oral Radiology, and Endodontics, vol. 86, no. 5, pp. 616-625, 1998.

[6] C. K. Chao, T. S. Sheen, W. Y. Shau, L. L. Ting, and M. M. Hsu, "Treatment, outcomes, and prognostic factors of ear cancer," Journal of the Formosan Medical Association, vol. 98, no. 5, pp. 314-318, 1999.

[7] D. M. Parham and D. A. Ellison, "Rhabdomyosarcomas in adults and children: an update," Archives of Pathology and Laboratory Medicine, vol. 130, no. 10, pp. 1454-1465, 2006.

[8] L. Wexler, W. Crist, and L. Helman, "Rhabdomyosarcoma and the undifferentiated sarcomas," in Principles and Practice of Pediatric Oncology, P. A. Pizzo and D. G. Poplack, Eds., pp. 939-963, Lippincot, Williams \& Wilkins, Philadelphia, Pa, USA, 4th edition, 2002.

[9] E. Barksdale and E. Wiener, "Rhabdomyosarcoma," in Pediatric Surgery, K. W. Ashcraft, J. P. Murphy, R. J. Sharp et al., Eds., pp. 942-953, Saunders, Philadelphia, Pa, USA, 3rd edition, 2000

[10] B. Viswanatha, "Embryonal rhabdomyosarcoma of the temporal bone," Ear, Nose and Throat Journal, vol. 86, no. 4, pp. 218-222, 2007.

[11] G. D. Potter, "Embryonal rhabdomyosarcoma of the middle ear in children.," Cancer, vol. 19, no. 2, pp. 221-226, 1966.

[12] W. Kukwa, P. Wojtowicz, B. Jagielska, G. Sobczyk, A. Kukwa, and A. M. Czarnecka, "Laryngeal embryonal rhabdomyosarcoma in an adult - a case presentation in the eyes of geneticists and clinicians," BMC Cancer, vol. 11, article 166, 2011.

[13] F. Khatami, A. Bazrafshan, M. Monajemzadeh, and M. Seyed, "Congenital embryonal rhabdomyosarcoma with prenatal onset," Iranian Journal of Pediatrics, vol. 18, no. 1, pp. 62-66, 2008. 


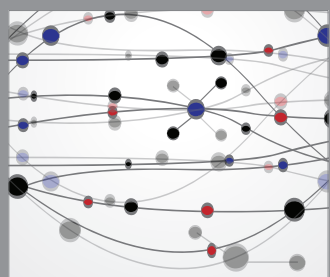

The Scientific World Journal
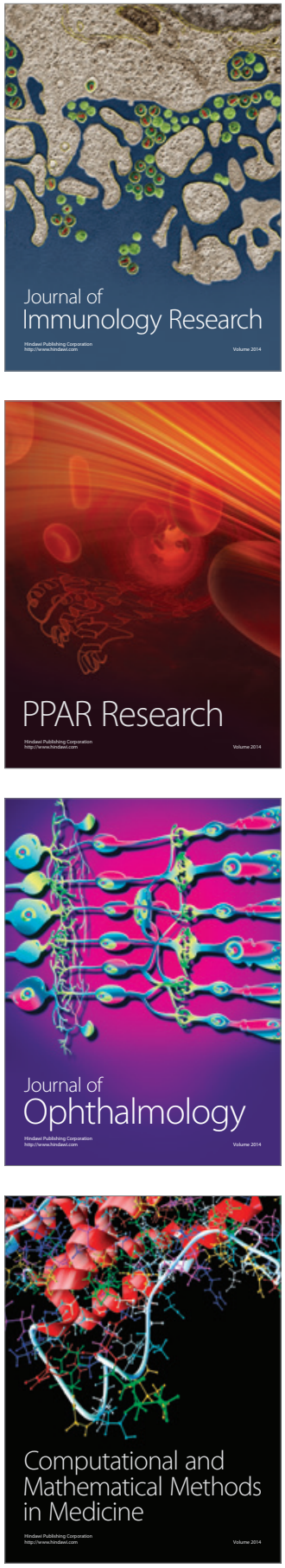

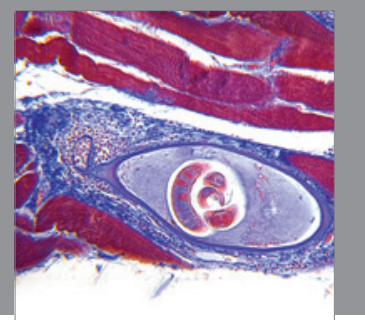

Gastroenterology

Research and Practice
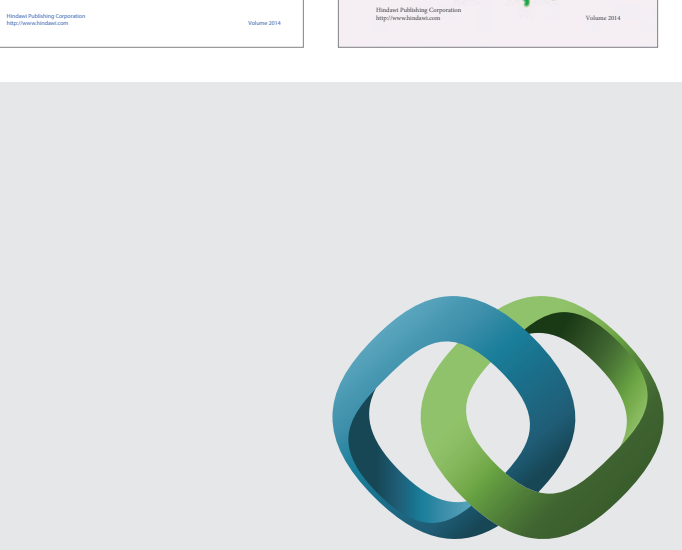

\section{Hindawi}

Submit your manuscripts at

http://www.hindawi.com
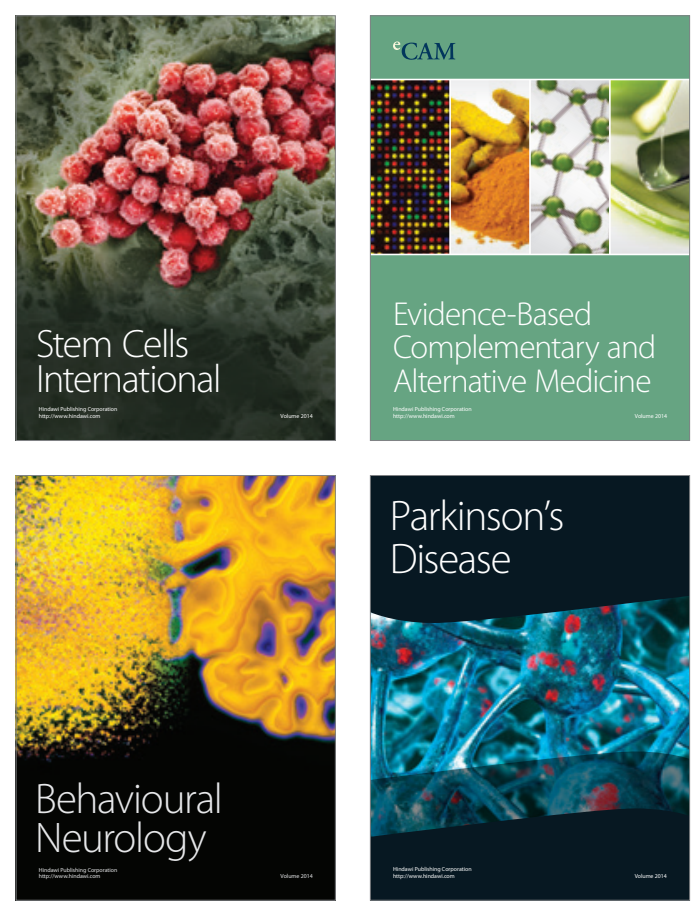

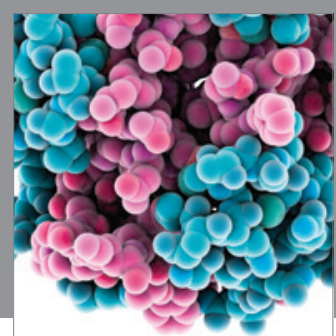

Journal of
Diabetes Research

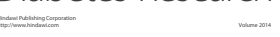

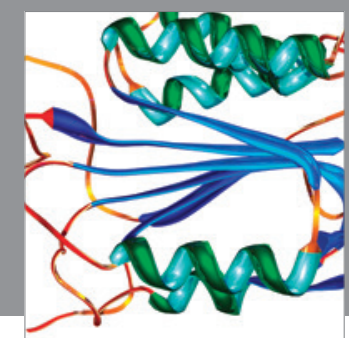

Disease Markers
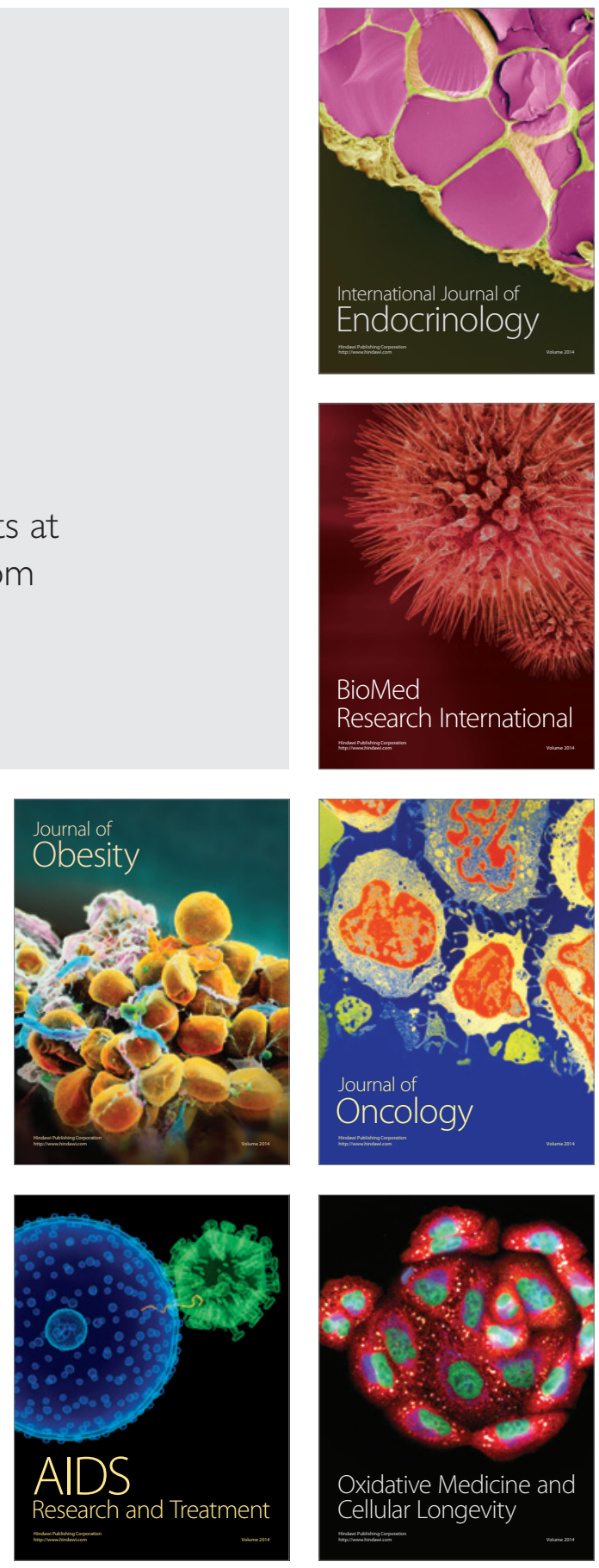